\title{
Visualizing Flow Fields Using Acoustic Doppler Current Profilers and the Velocity Mapping Toolbox
}

\section{Beyond Discharge}

The purpose of this fact sheet is to provide examples of how the U.S. Geological Survey is using acoustic Doppler current profilers for much more than routine discharge measurements. These instruments are capable of mapping complex three-dimensional flow fields within rivers, lakes, and estuaries. Using the Velocity Mapping Toolbox to process the ADCP data allows detailed visualization of the data, providing valuable information for a range of studies and applications.

\section{What Is an Acoustic Doppler Current Profiler and How Does it Work?}

Much like a radar gun is used for determining the speed of a moving vehicle, the acoustic Doppler current profiler (ADCP) relies on the Doppler effect to measure the speed and direction of flowing water. The ADCP transmits pulses of sound at a known frequency into the water column along diverging beams (fig. 1). Particles being carried by currents reflect the sound back to the ADCP (much like a car reflects the radar gun signal). The ADCP receives the reflected sound using the same transducers that transmitted the original sound pulses and then analyzes these data. Changes in frequency of the sound returning to the ADCP are related to the speed at which each particle is moving (that is, the Doppler effect). Along with timing information, pitch and roll data, speed of sound estimates, and depth measurements, the ADCP uses sophisticated algorithms to measure a $3 \mathrm{D}$ velocity field based on information received from its four beams. The ADCP also records independent measurements of depth from each transducer for every sample. With the ability to sample several times a second, an ADCP provides a more efficient means of gathering detailed hydrodynamic data for studies within the U.S. Geological Survey (USGS).

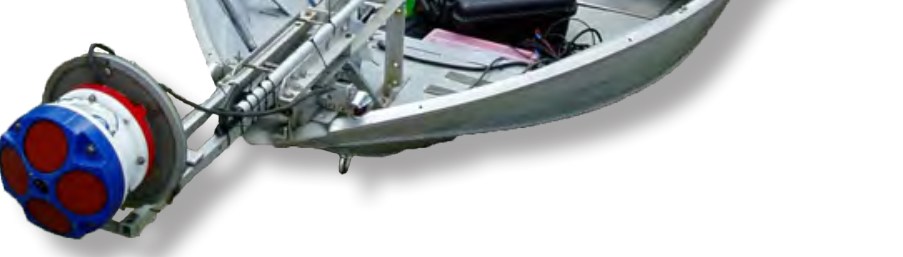

\section{The Velocity Mapping Toolbox (VMT)}

The Velocity Mapping Toolbox (VMT) is a Matlab ${ }^{\circledR}$-based software for processing and visualizing ADCP data collected in rivers or other bodies of water. VMT allows processing, visualization, and analysis of a range of ADCP datasets and includes utilities to export ADCP data to files compatible with ArcGIS ${ }^{\circledR}$, Tecplot ${ }^{\circledR}$, and Google Earth $^{\circledR}$. The software can be used to explore patterns of 3D fluid motion through several methods for calculation of secondary flows (Rhoads and Kenworthy, 1998; Lane and others, 2000). The software also includes capabilities for analyzing the acoustic backscatter and bathymetric data from the ADCP. A user-friendly graphical user interface (GUI) enhances program functionality and provides ready access to 2 - and 3D plotting functions, allowing display and interrogation of velocity, backscatter, and bathymetry data. See Parsons and others (2013) for more information.

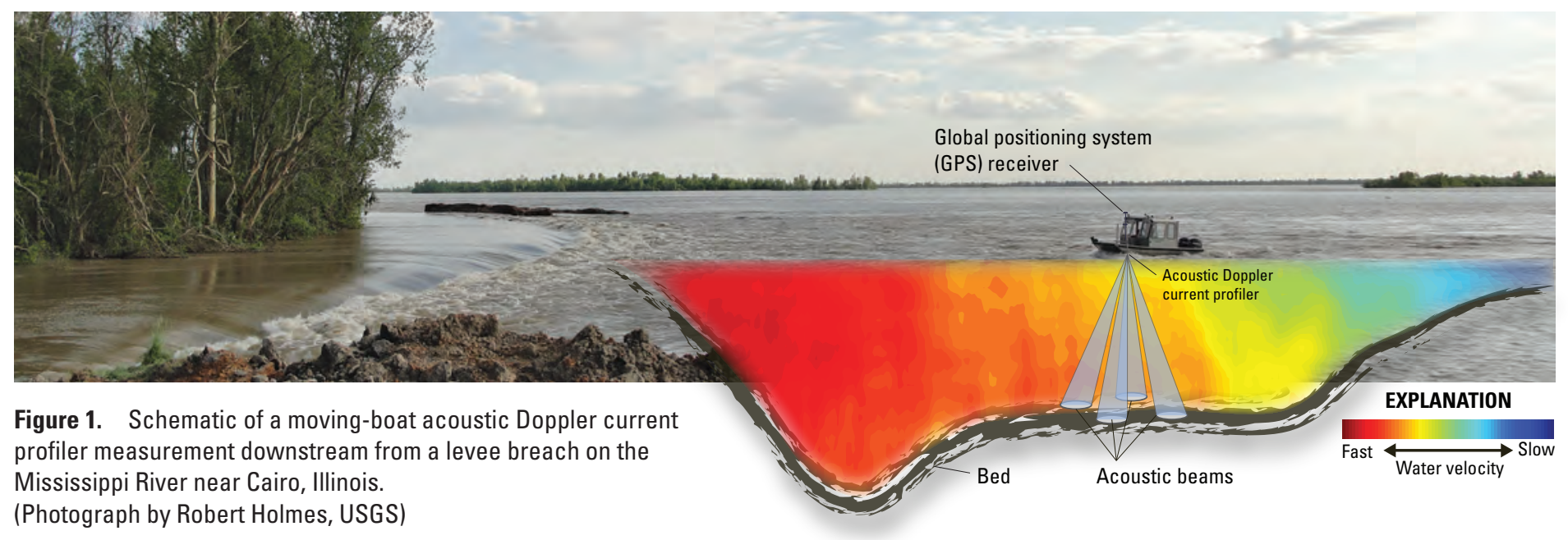




\section{Mapping Depth- and Layer-Averaged Velocities}

Spatial distributions of depth- and layer-averaged velocities are important when trying to understand large-scale circulation patterns in lakes and reservoirs. Because many lakes and reservoirs are thermally stratified for certain months of the year, a true understanding of the lake circulation requires an analysis of the currents on a layer-by-layer basis. VMT allows users to extract, average, and visualize velocity data from any user-defined layer of interest. In doing so, the user may find very different circulation patterns above and below the thermocline (fig. 2). These patterns may not be apparent when averaging data over the full depth of flow.

In unstratified water bodies, such as rivers and well-mixed lakes, depth-averaged velocities can provide valuable information about flow structure, shear, and interaction of the flow with the bed, banks, and structures. Such interaction is evident in figure 3 in which the alongshore currents in Lake Erie interact with shoreline structures to produce a large zone of recirculation that traps inflow from a tributary (and the constituents transported therein) along a beach front. Circulation patterns are often hidden in the noise of the data, but the averaging routines in VMT reduce the noise and allow these patterns to be seen. VMT allows depth- and layer-averaged velocity data to be exported in a georeferenced format for direct comparison to output from hydrodynamic models or for inclusion in analyses using geographic information systems (GIS).
Surface-water temperature, in degrees Celsius

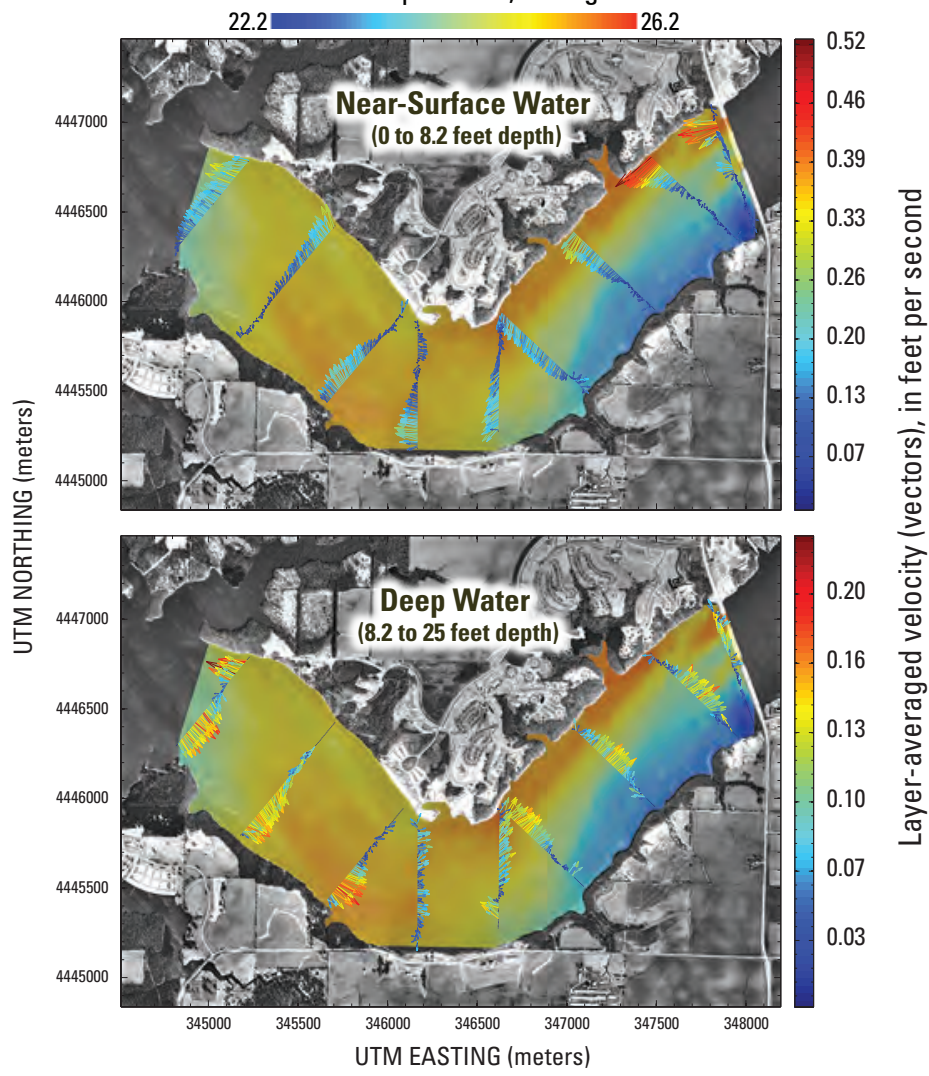

Figure 2. Layer-averaged currents showing the thermal plume from a nuclear powerplant in one section of Clinton Lake, Illinois, a 5,000-acre cooling reservoir, October 6, 2008. Note the opposing currents in the two layers.

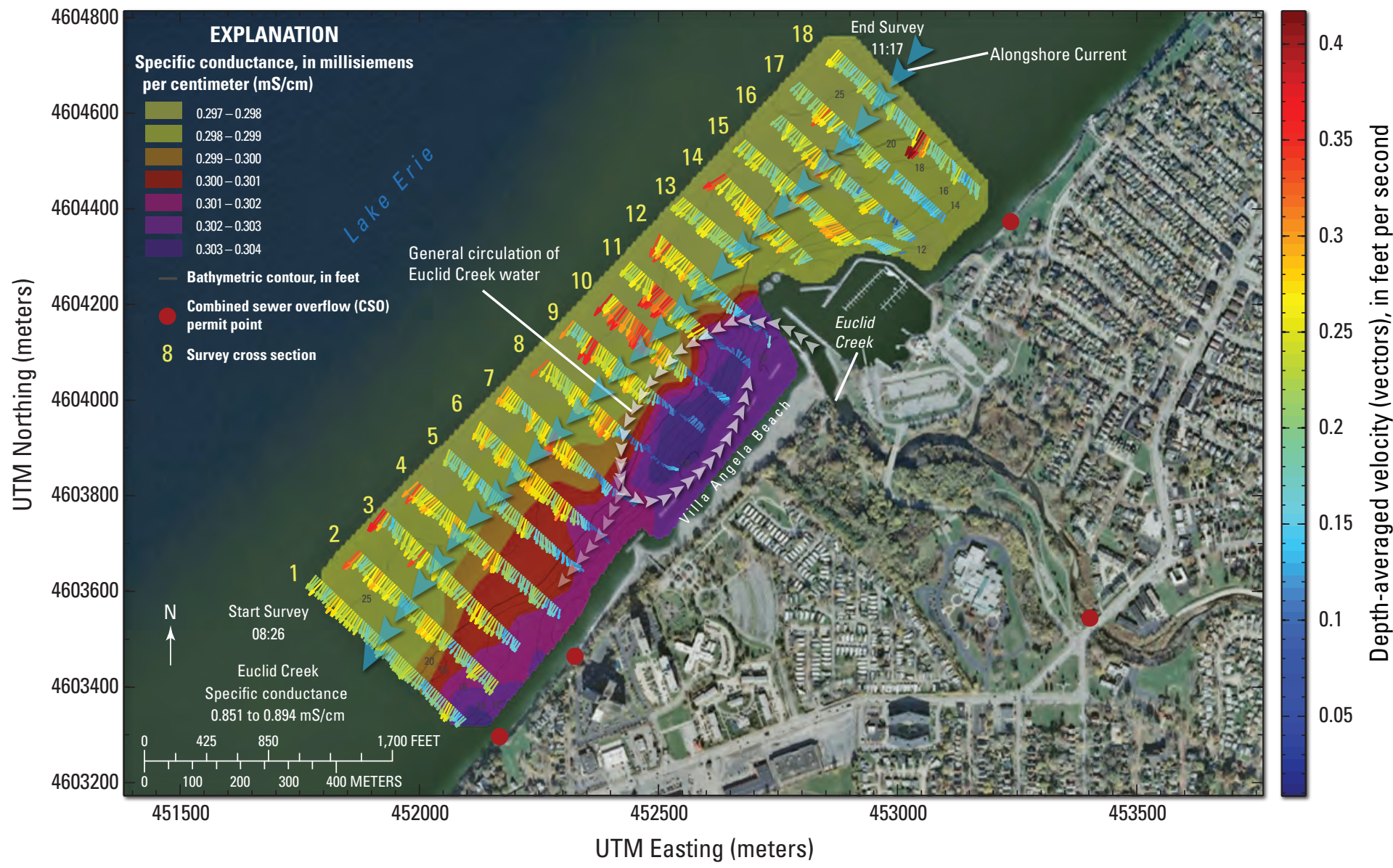

Figure 3. Depth-averaged currents and distribution of near-surface specific conductance in coastal Lake Erie in the vicinity of Villa Angela Beach and Euclid Creek, Ohio, on September 11, 2012. Produced in VMT using data from an ADCP and supplementary specific conductance data from an autonomous underwater vehicle that completed a simultaneous 3D survey. 


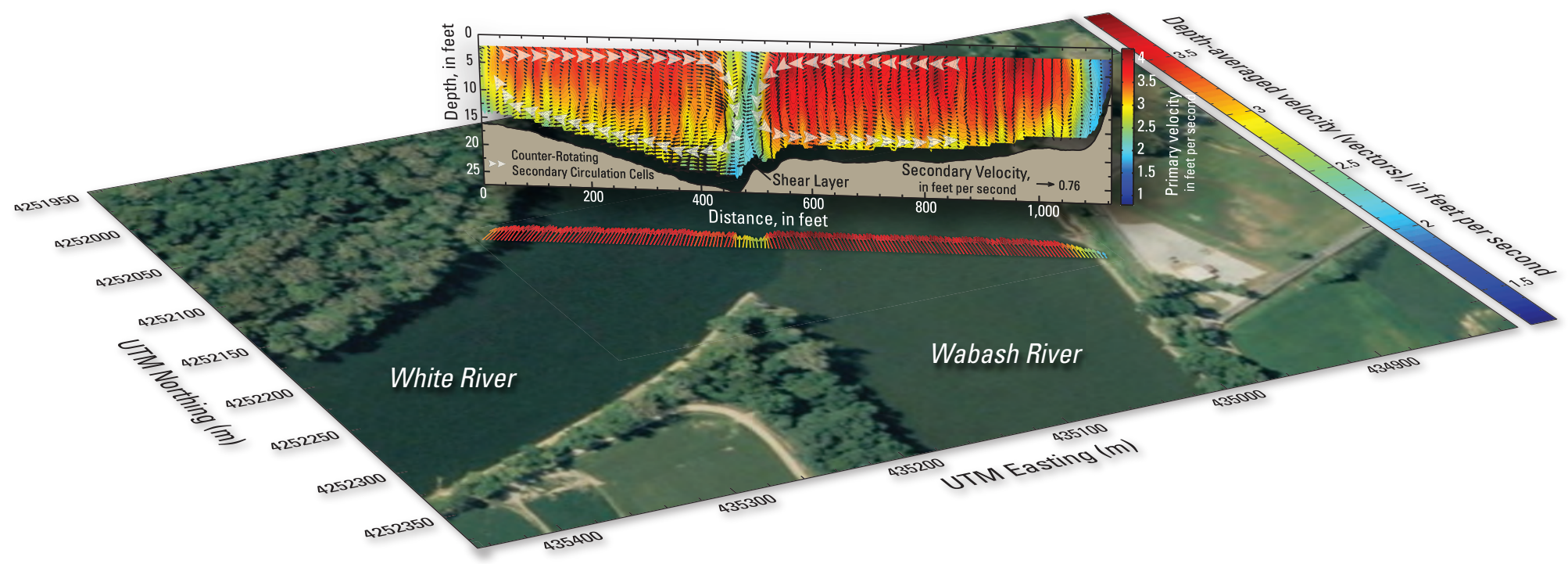

Figure 4. Depth-averaged velocity and primary and secondary velocities (Rozovskii definition) in the confluence of the White and Wabash Rivers along the Illinois and Indiana border, January 12, 2008. Produced in VMT using data from an ADCP and additional formatting using a graphics design program.

\section{Mapping Primary and Secondary Circulation Patterns in Rivers}

Velocities oriented perpendicular to the streamwise, or primary flow, direction are called secondary velocities and are important for understanding sediment transport and mixing in rivers. VMT computes primary and secondary velocities using several conventions (Lane and others, 2000) and allows users to easily switch between conventions. Some conventions, such as the Rozovskii definition, are generally best suited for bifurcations and confluences (fig. 4), while others like the "zero net secondary discharge" definition are best suited for meander bends (fig. 5). VMT allows users to place secondary flow vectors atop a contour variable, such as primary flow velocity or acoustic backscatter, for analysis.

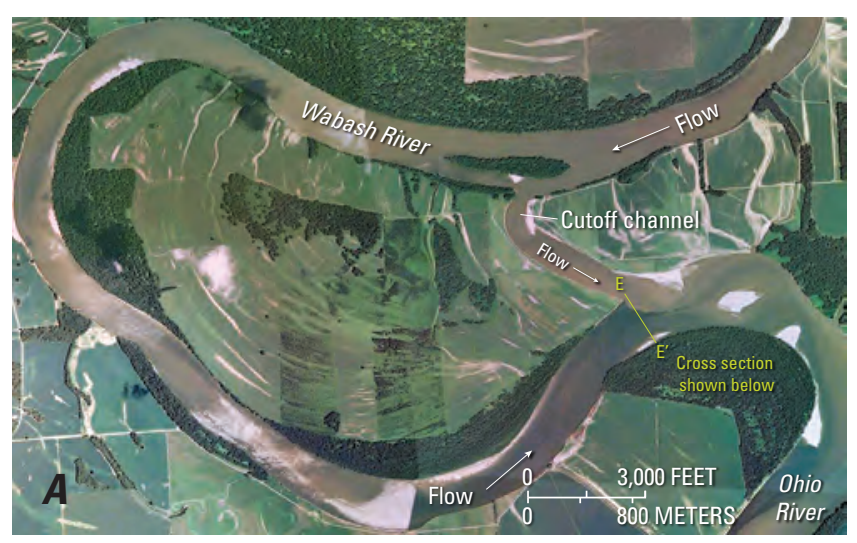

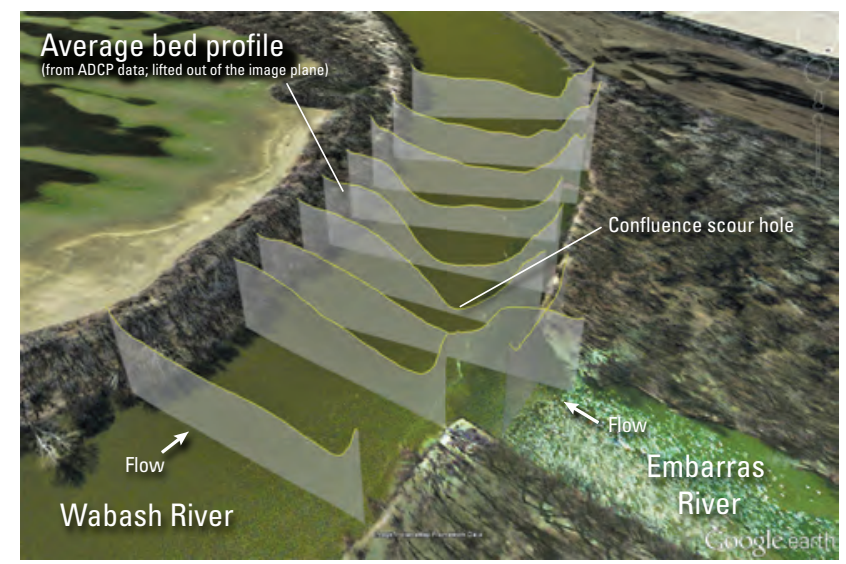

Figure 6. Screen shot of average bed profiles through the confluence of the Wabash and Embarras Rivers, May 23, 2006, visualized in 3D in Google Earth ${ }^{\circledR}$. Google Earth ${ }^{\circledR}$ KMZ files were exported from VMT (each section is an average of four transects collected with an ADCP).

\section{Bathymetry From an ADCP}

Each of the transducers of an ADCP serves as a single beam echo sounder and provides an independent measurement of the water depth. VMT allows the bathymetry data to be averaged to form a single representative bed profile at each cross section (fig. 6) or exported as individual point data from each transducer (corrected for heading, pitch, and roll). These data can be useful for understanding the morphology of a river or for developing hydrodynamic models.

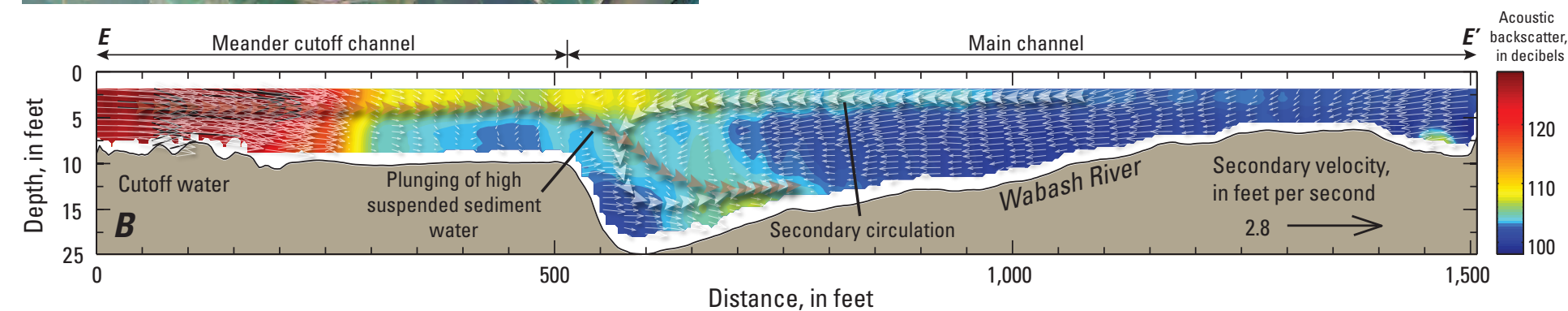

Figure 5. (A) An overview image of the Wabash River and a developing meander cutoff channel from June 2008 and (B) Acoustic backscatter (surrogate for suspended sediment) overlaid by secondary flow vectors at the confluence of the Wabash River and the cutoff channel, January 7, 2009. Produced in VMT using data from an ADCP and additional formatting using a graphics design program. Secondary flow vectors computed using the "zero net secondary discharge" definition. 


\section{Utilizing a Geographic Information System (GIS) Framework for ADCP Data}

Studies in natural and environmental science often require a cross-disciplinary approach and integration of geological, hydrological, hydrodynamic, biological, and meteorological datasets into a common framework for analysis. Because of the general spatial heterogeneity of these datasets, the GIS framework is often used due to its ability to handle georeferenced data from a variety of sources. Because many biological and morphological processes in surface-water bodies depend on currents, it is important that ADCP data be readily accessible to the GIS community. Using a standalone utility, VMT allows users to extract depth- or layer-averaged ADCP data to a GIS-compatible format for easy import into GIS software packages. Accessible data include not only 3D water velocity but also individual depth soundings from each ADCP transducer, acoustic backscatter (high backscatter can be correlated with high suspended sediment), and surface-water temperature measured using the thermistor in the head of the ADCP (see fig. 2). To reduce uncertainty of the data and provide a clearer representation of the flow, the VMT utility allows temporal averaging. Data input into this utility need not be transect based and can include, for example, streamwise profiles of rivers (Murphy and Jackson, 2013), serpentine surveys of a reach (fig. 7) or water body, or a series of stationary at-a-point measurements.

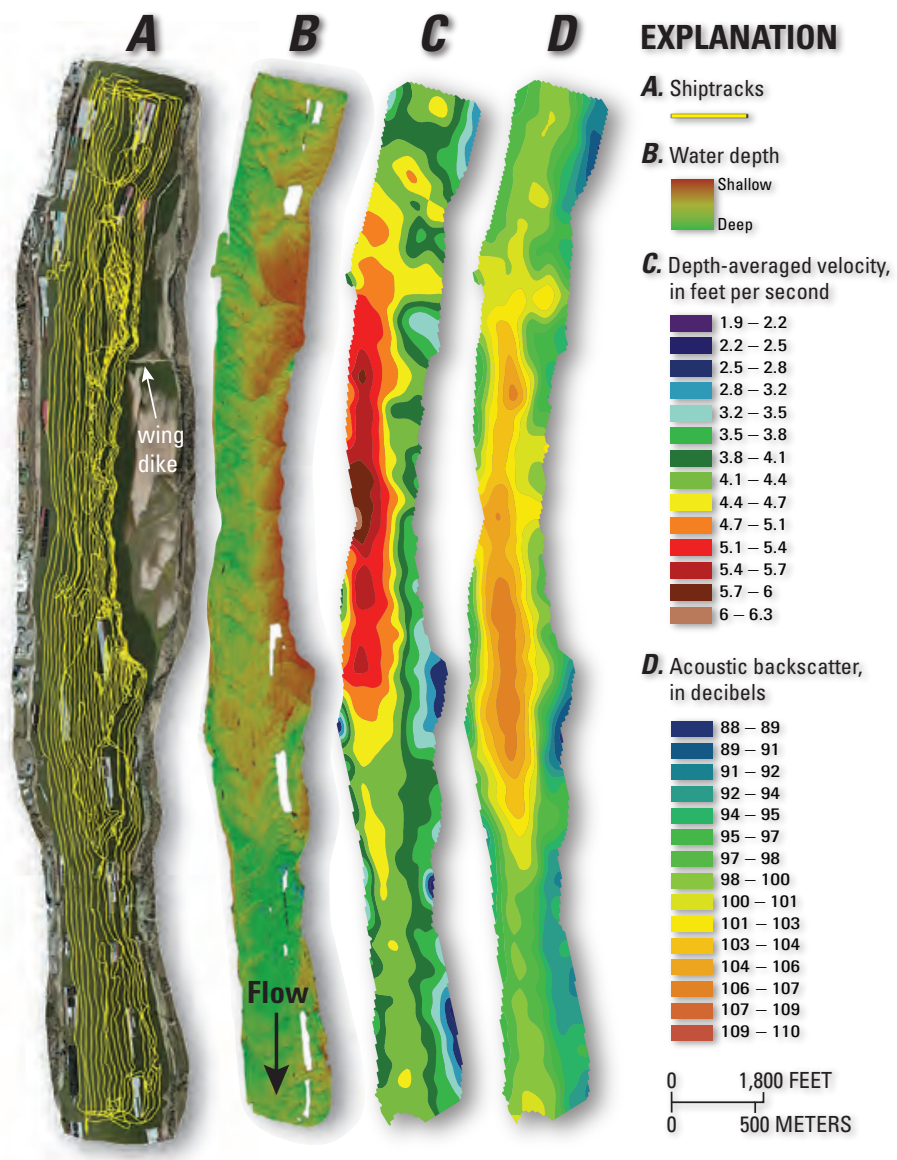

Figure 7. A 3-mile reach of the Mississippi River near St. Louis, Missouri, showing $(A)$ survey shiptracks, $(B)$ multibeam bathymetry, $(C)$ depth-averaged velocity, and (D) acoustic backscatter. Data collected November 2-3, 2010, with an ADCP (127,000 samples averaged over 20 -second intervals). Note the acceleration of the flow in response to channel training structures and the associated increase in backscatter due to sediment resuspension. Evidence of the flow response to bedforms is also present.

\section{Additional Examples of Applications of VMT and Similar Software}

Find more examples, learn more about VMT, and download the program at http://hydroacoustics.usgs.gov/movingboat/VMT/ VMT.shtml.

\section{Studies of Particular Interest:}

Czuba, J.A., Best, J.L., Oberg, K.A., Parsons, D.R., Jackson, P.R., Garcia, M.H., and Ashmore, P., 2011, Bed morphology, flow structure, and sediment transport at the outlet of Lake Huron and in the upper St. Clair River: Journal of Great Lakes Research, v. 37, p. 480-493.

Dinehart, R.L., and Burau, J.R., 2005, Averaged indicators of secondary flow in repeated acoustic Doppler current profiler crossings of bends: Water Resources Research, v. 41, 18 p.

\section{Acknowledgments}

The author wishes to thank Kevin Johnson (U.S. Geological Survey), Jim Best and Bruce Rhoads (University of Illinois at Urbana-Champaign), and Dan Parsons (University of Hull, UK) for contributing data to this publication.

\section{References Cited}

Lane, S.N., Bradbrook, K.F., Richards, K.S., Biron, P.M., and Roy, A.G., 2000, Secondary circulation cells in river channel confluences: Measurement artefacts or coherent flow structures?: Hydrological Processes, v. 14, no. 11-12, p. 2047-2071.

Murphy, E.A., and Jackson, P.R., 2013, Hydraulic- and water-quality data collection for the investigation of Great Lakes tributaries for Asian carp spawning and egg-transport suitability: U.S. Geological Survey Scientific Investigations Report 2013-5106, 30 p.

Parsons, D.R., Jackson, P.R., Czuba, J.A., Engel, F.L., Rhoads, B.L., Oberg, K.A., Best, J.L., Mueller, D.S., Johnson, K.K., and Riley, J.D., 2013, Velocity Mapping Toolbox (VMT): A processing and visualization suite for moving-vessel ADCP measurements: Earth Surface Processes and Landforms, online Early View, 17 p., DOI: 10.1002/ esp.3367.

Rhoads, B.L., and Kenworthy, S.T., 1998, Time-averaged flow structure in the central region of a stream confluence: Earth Surface Processes and Landforms, v. 23, p. 171-191.

Front page banner imagery: Visualization of flow (vectors) and acoustic backscatter (contours) in the Rio Paraná, near Santa Fe, Argentina, on September 18, 2009. High backscatter (red) can be correlated with high suspended sediment, and banner shows an ejection of sediment from the bed (red plume) as flow separates in the lee of a dune and the subsequent formation as a "boil" on the river surface.

Front page boat photograph: Manned boat equipped with an ADCP and differential GPS receiver. The bow mount is stowed in the horizontal position for transport and is rotated to the vertical position for measurement. Photograph by Paul Baker, USGS.

Any use of trade, product, or firm names is for descriptive purposes only and does not imply endorsement by the U.S. Government.

P. Ryan Jackson, Hydrologist

U.S. Geological Survey, Illinois Water Science Center pjackson@usgs.gov

For information contact:

U.S. Geological Survey, Office of Surface Water

415 National Center, Reston, VA 20192

(703) 648-5301, http://hydroacoustics.usgs.gov 